\title{
Efficient reduction of electron-deficient alkenes enabled by a photoinduced hydrogen atom transfer
}

\author{
Natalia A. Larionova, Jun Miyatake Ondozabal and Xacobe C. Cambeiro* \\ Department of Chemistry, School of Biological and Chemical Sciences, Queen Mary University of London. Mile End Rd, London E1 4NS (UK). \\ *x.cambeiro@qmul.ac.uk
}

\begin{abstract}
Direct hydrogen atom transfer from a photoredox-generated Hantzsch ester radical cation to electron-deficient alkenes has enabled the development of an efficient formal hydrogenation under mild, operationally simple conditions. The HAT-driven mechanism, key to circumvent the problems associated with the low electron affinity of alkenes, is supported by experimental and computational studies. The reaction is applied to a variety of cinnamate derivatives and related structures, irrespective of the presence of electron-donating or electron-withdrawing substituents in the aromatic ring and with good functional group compatibility.
\end{abstract}

\section{Introduction}

The hydrogenation of $\mathrm{C}-\mathrm{C}$ multiple bonds and related reductive transformations are among the most important processes in chemical industry. ${ }^{1}$ In particular, transfer hydrogenation, which avoids the use of hydrogen gas, is of much practical interest in both industrial and laboratory settings, and the development of new methods and strategies is of continued importance. ${ }^{2}$

The recent fast development of photocatalysis has resulted in the discovery of a wide variety of reductive, oxidative and redox-neutral transformations. ${ }^{3}$ Photocatalytic reduction methods have been explored in a number of instances, and actually some of the pioneering research in photocatalysis dealt with the formal hydrogenation of alkenes using a dihydropyridine ( $N$-benzyl 1,4-dihydronicotinamide, BNAH) as the reductant. ${ }^{4}$ However, this early work was handicapped by a very narrow substrate scope - the reaction only worked on extremely electron-deficient alkenes bearing at least two electron-withdrawing groups (Scheme 1A). ${ }^{5}$ This is attributed to the low electron affinity of alkenes, which results in direct electron transfer reductions being difficult. For other functional groups, similar limitations have been overcome by activating the substrate with Lewis or Brønsted acid additives or co-catalysts, which make it more electron-deficient. ${ }^{6}$ However, to the best of our knowledge, such strategies have not been successfully applied to the formal hydrogenation of alkenes. ${ }^{7}$ On a different approach, reduction could be forced by using catalytic systems with increased reductive power, for example by the exploitation of two-photon excited states $^{8}$ or combining electro- and photocatalysis. ${ }^{9}$ Nevertheless, the possible reduction of other functional groups under these very strongly reducing conditions limits the scope of such strategies. One recent report has described the application of a two-photon strategy for the formal hydrogenation of 1,2diarylethylenes by sequential electron and proton transfer reactions (Scheme $1 \mathrm{~A}) .{ }^{10}$

Finally, an alternative strategy to achieve the reduction of alkenes circumventing the issue of their low electron affinity would be to exploit hydrogen atom transfer (HAT) reactions. ${ }^{11}$ Thus, a catalytic system capable of promoting the transference of a $\mathrm{H}$ atom to an alkene would provide an easy route for their reduction without requiring highly reducing potentials (Scheme 1B). HAT is frequently invoked in light-promoted hydrofunctionalisation, ${ }^{12}$ always in a termination step where an organic radical abstracts $\mathrm{a} \mathrm{H}$ atom from radical cations of dihydropyridines, such as Hantzsch ester (HE), or other donors. ${ }^{13,14}$ However, methodologies using HAT into a stable, closed-shell compound have not been reported to date. Herein we report an efficient and operationally simple reduction of cinnamate derivatives under mild conditions, initiated by HAT from a photoredox-generated Hantzsch ester radical cation.

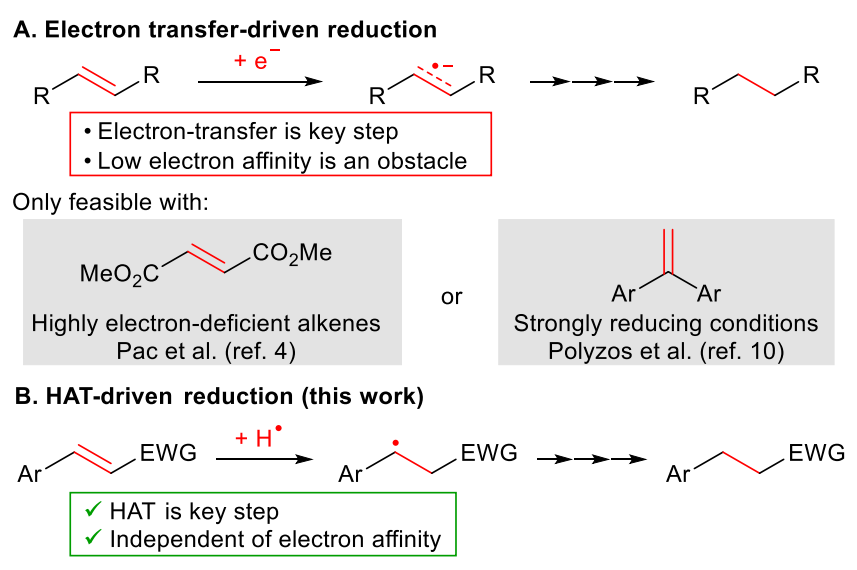

Scheme 1. Strategies for the photoreduction of alkenes promoted by visible light

\section{Results and discussion}

We started our investigation by studying the reduction of methyl cinnamate (1a) as a model substrate with combinations of known photocatalysts and potential hydrogen atom donors $^{13}$ (summary in Table 1, entries 1-5). Gratifyingly, we found that $\left[\operatorname{Ir}(\mathrm{ppy})_{2}(\mathrm{dtbbpy})\right] \mathrm{PF}_{6}$ (Ir1) was indeed capable of promoting the reaction with either ${ }^{i} \operatorname{Pr}_{2} \mathrm{NEt}$, 1,4dihydronicotinamide (BNAH) or Hantzsch ester (HE) as the 
reductant and $\mathrm{H}$ atom donor, with $\mathrm{HE}$ providing quantitative yield (entry 1). Other similar photocatalysts such as $\mathrm{Ru}(\mathrm{bpy})_{3} \mathrm{Cl}_{2}$ and $\operatorname{Ir}(\mathrm{ppy})_{3}$ did not provide virtually any conversion to $\mathbf{2 a}$. $^{15}$

Application of these conditions to the more electron-rich substrate $\mathbf{1} \mathbf{b}$ resulted initially in a significant erosion of the yield (entry 6). Nonetheless, re-optimisation of the reductant to substrate ratio (entry 7) and concentration (entry 8 ) brought the yield back to satisfactory levels (91\%, entry 8 ). As expected, control experiments in the absence of the Ir photocatalyst (entry 9) or in the dark (entry 10) showed that both are essential for the reaction to proceed. It is worth noting that the reduced form of Ir 1 is not predicted to be a strong enough reductant to perform a SET to $1 \mathrm{a}\left(\mathrm{E}_{\frac{1}{2}}(\operatorname{Ir} 1)=-1.51 \mathrm{~V}(\mathrm{MeCN})\right)^{3 \mathrm{~d}}$ $E_{1 / 2}(1 a)=-1.87 \mathrm{~V}$, see below for further discussion).

Table 1. Summary of reaction optimisation. ${ }^{a}$
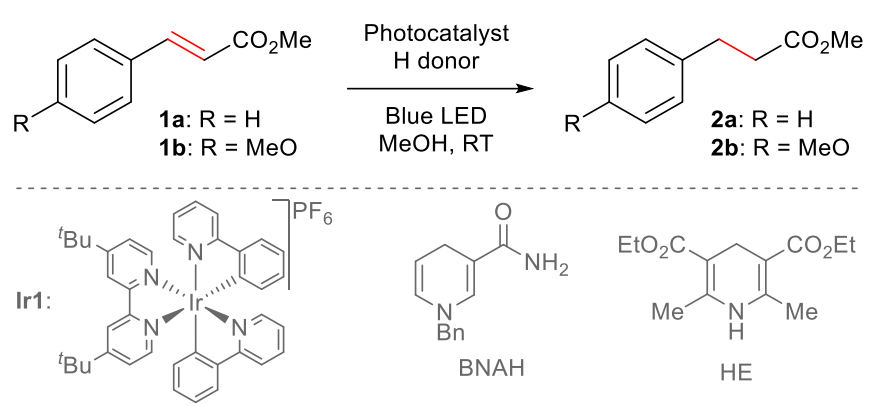

\begin{tabular}{|c|c|c|c|}
\hline Entry & Substrate & Conditions & Yield $(\%)^{b}$ \\
\hline 1 & 1a & 50 mM, Ir1 2.5 mol\%, HE (1 equiv) & 100 \\
\hline 2 & & $\mathrm{Ru}(\mathrm{bpy})_{3} \mathrm{Cl}_{2}$ as the catalyst & 1 \\
\hline 3 & & $\operatorname{Ir}(\mathrm{ppy})_{3}$ as the catalyst & 2 \\
\hline 4 & & $\mathrm{EtN}^{i} \mathrm{Pr}_{2}$ as the reductant & 36 \\
\hline 5 & & $\mathrm{BNAH}$ as the reductant & 42 \\
\hline 6 & $1 b$ & As entry 1 & 64 \\
\hline 7 & & HE (2 equiv) & 70 \\
\hline 8 & & 12.5 mM, HE (2 equiv) & 91 \\
\hline 9 & $1 b$ & No photocatalyst ${ }^{c}$ & 1 \\
\hline 10 & & $\operatorname{Dark}^{d}$ & 0 \\
\hline
\end{tabular}

Ir1: [Ir(ppy $)_{2}(\mathrm{dtbbpy}) \mathrm{PFF}_{6} .{ }^{a}$ Reactions run with substrate $1(0.1 \mathrm{mmol})$, reductant (see table) and catalyst ( $2.5 \mathrm{~mol} \%$ ) at RT in $\mathrm{MeOH}$, following general procedure $\mathrm{B}$ (see ESI). ${ }^{b}$ Yield determined by ${ }^{1} \mathrm{H}$ NMR using an internal standard. ${ }^{c}$ Reaction performed at $50 \mathrm{mM}$ concentration of $\mathbf{1 b}$. ${ }^{d}$ Reaction performed at $25 \mathrm{mM}$ concentration of $\mathbf{1 b}$.

Then, we set out to explore the substrate scope and limitations of our method (Table 2). The photoreduction worked to high yields with a wide variety of cinnamate derivatives bearing different substituents on the aryl ring (2a-u). Electron-donating $\mathrm{MeO}$ group was tolerated at all three possible positions ( $\mathbf{2} \mathbf{b}-\mathbf{d})$, as well as electron-withdrawing $\mathrm{CF}_{3}(\mathbf{2} \mathbf{e}-\mathbf{g})$. Likewise, no steric influence on reaction yield was apparent from substitution at the ortho- position (2k-m). The reaction was compatible with halogen substituents ( $\mathbf{2} \mathbf{h}$ -

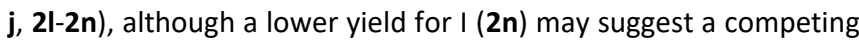
reduction of the $\mathrm{C}-\mathrm{I}$ bond. In the case of $\mathrm{Br}$, para-substituted compound ( $\mathbf{2} \mathbf{h})$ was only obtained in moderate yield, in contrast with the good results for the ortho- and meta- analogues (60\% and $97 \%$, respectively, for $\mathbf{2} \mathbf{j}$ and $\mathbf{2 i}$ ).
Table 2. Substrate scope and limitations. ${ }^{a}$

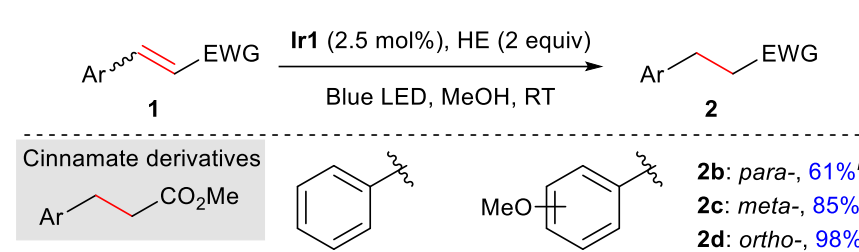

2a: $87 \%$

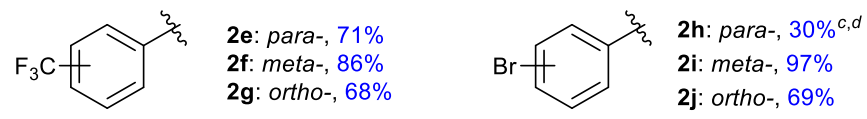<smiles>Cc1ccccc1C</smiles>

2k: $91 \%$<smiles>Cc1ccccc1F</smiles>

2l: $95 \%$<smiles>Cc1ccccc1Cl</smiles>

2m: $85 \%$<smiles>Cc1ccccc1I</smiles>

2n: $46 \%^{c}$<smiles>[Z6]c1ccc(C(=O)O)cc1</smiles><smiles>Cc1ccc(CNC(=O)c2ccc(C(C)(C)C)cc2)cc1</smiles><smiles></smiles>

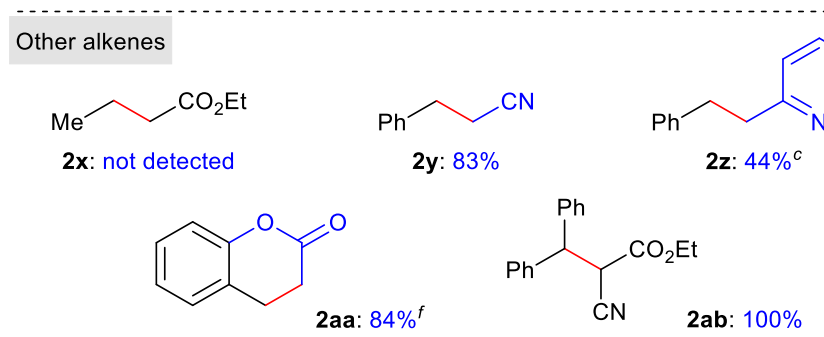

a Unless stated otherwise, reactions were run with substrate $1(0.2 \mathrm{mmol}$, $0.025 \mathrm{M}), \mathrm{HE}$ (2 equiv) and catalyst Ir1 (2.5 mol\%) following general procedure $B$ (see ESI). Yields are of isolated product unless otherwise noted. ${ }^{b}$ NMR yield in this case was significantly higher (89\%). ${ }^{c}$ Yield determined by ${ }^{1} \mathrm{H}$ NMR using an internal standard. ${ }^{d}$ The ethyl ester was used in this case instead of methyl. $e$ Starting from the corresponding ethyleneglycol acetal. ${ }^{f} \mathrm{MeCN}$ was used as the solvent.

The reaction tolerated unprotected alcohols (2p), carboxylic acids $\mathbf{2} \mathbf{r})$ and amines, even when containing free $\mathrm{NH}$ bonds $(\mathbf{2 t}$ and $\mathbf{2} \mathbf{u})$, although phenol and aniline provided decreased yields ( 20 and $\mathbf{2 s}$ ). Aldehyde-substituted product $\mathbf{2 q}$ could be obtained by performing the reaction with the corresponding ethyleneglycol acetal, which was deprotected in situ during work-up.

Replacing the aryl group in the cinnamate ester structure for heterocycles such as pyridyl or furyl resulted in low yields of product $(2 \mathbf{v}-\mathbf{w})$ and the reaction did not proceed at all in the absence of an aromatic group (2x). 

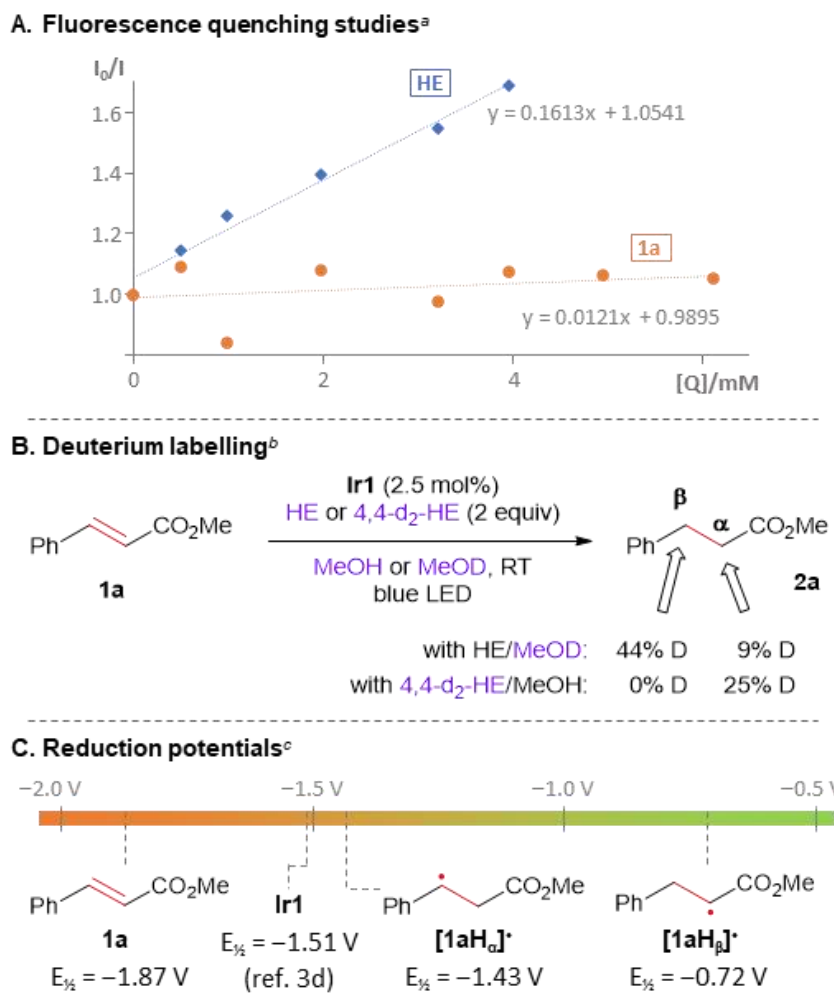

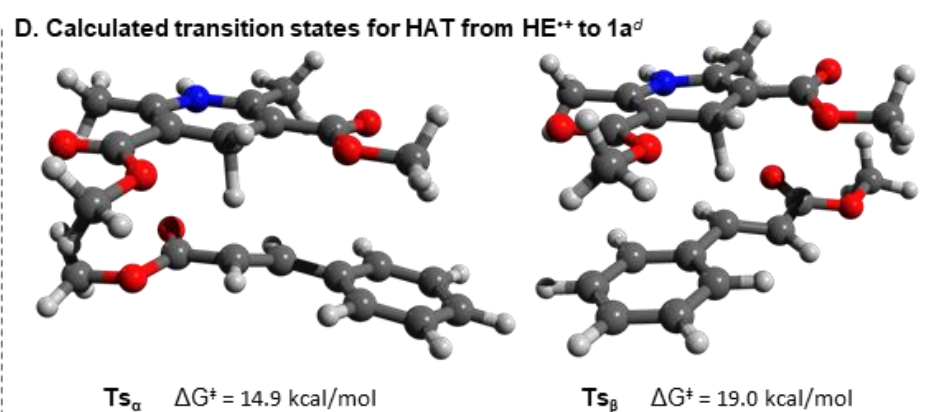

(M06-2X/6-31+G(d,p))

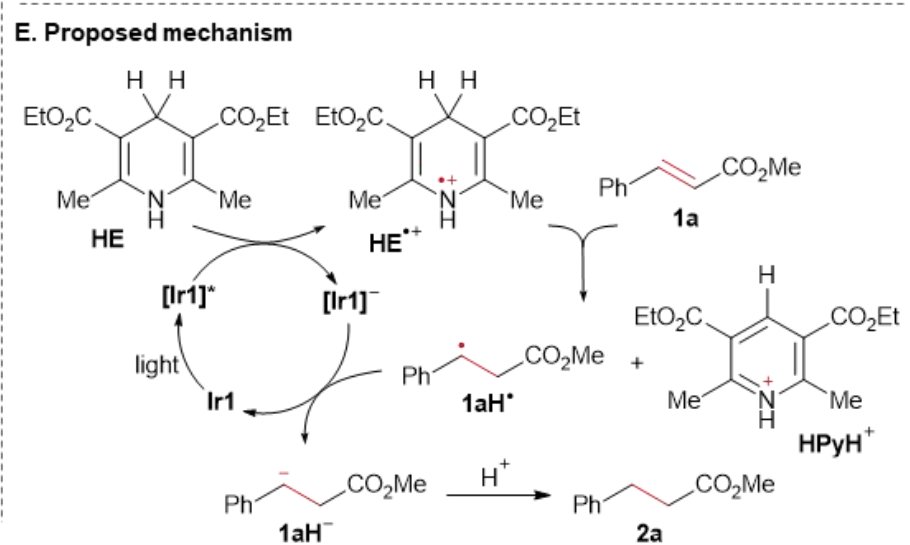

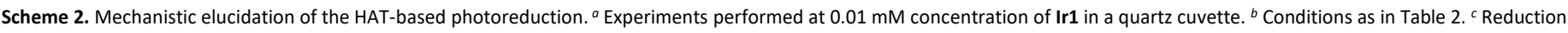

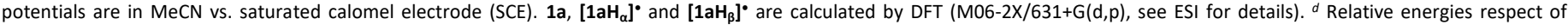
independent starting materials (M06-2X/6-31+G(d,p), see ESI for details).

Moving away from the methyl cinnamate structure, cinnamonitrile (2y) and coumarin (2aa) were both efficiently reduced under our reaction conditions Finally, our method worked well for the reduction of a tetrasubstituted alkene (2ab), highlighting its robustness with respect to steric hindrance.

To probe the mechanism of the reaction we decided to perform a series of additional experiments, summarised in Scheme 2. Firstly, Stern-Volmer quenching experiments (Scheme 2A) showed fluorescence quenching by $\mathrm{HE}$ to significantly outcompete quenching by substrate 1 a (quencher rate coefficient $\left.\mathrm{k}_{\mathrm{q}(\mathrm{HEH})} / \mathrm{k}_{\mathrm{q}(\mathbf{1 a})} \approx 13\right) .{ }^{16}$ This confirmed our expectation that the reaction likely starts with a reductive quenching of the excited catalyst [Ir1]* by $\mathrm{HE}$ to give the reduced form of the catalyst [Ir1] ${ }^{-}$together with formation of the Hantzsch ester radical cation $[\mathrm{HE}]^{\bullet+} .^{17}$

Then, we explored the use of deuterium labelling (Scheme 2B) to assess the possibility of the reduction proceeding through a sequence of electron and proton transfer events, as previously proposed for related alkene photoreductions.4,5,10 The photoreduction of $1 \mathrm{a}$ using $\mathrm{MeOD}$ instead of $\mathrm{MeOH}$ led to formation of product $\mathbf{2 a}$ with $9 \%$ incorporation of deuterium at the $\beta$-position and $44 \%$ at $\alpha$ (out of an expected maximum of $50 \%$ ). Conversely, the same reaction in $\mathrm{MeOH}$ with 4,4- $\mathrm{d}_{2}-$ $\mathrm{HE}$ resulted in $\mathbf{2 a}$ with $25 \%$ deuteration exclusively at $\alpha$. These results are in clear contrast with those previously reported for reductions based on consecutive electron and proton transfer. ${ }^{18}$ The extent of deuterium incorporation in these experiments combined with the marked regioselectivity strongly supports a mechanism where the $\alpha-\mathrm{H}$ would be incorporated by a HAT from a HE derivative, while the $\beta-\mathrm{H}$ would come from the solvent. The incomplete deuteration may be attributed to adventitious $\mathrm{H}_{2} \mathrm{O}$, and some extent of $\mathrm{H} / \mathrm{D}$ exchange between the reagents and solvent during the reaction.

With these data in hand, we contemplated two distinct possible mechanisms -either: (a) The reaction is initiated by SET to give, after protonation, an intermediate radical species, which is in turn transformed into the final product 2 by HAT from $[\mathrm{HE}]^{\bullet+}$; or (b) the reaction is initiated by HAT from $[\mathrm{HE}]^{\bullet+}$ to $1 \mathbf{a}$, giving an intermediate radical species, which is then transformed into $\mathbf{2 a}$ by consecutive SET and $\mathrm{H}^{+}$transfer. Interestingly, as mentioned above, while the role of $[\mathrm{HE}]^{\cdot+}$ as a $\mathrm{H}$ atom donor is frequently proposed in the literature, its involvement is always mentioned in termination steps, reacting with another radical intermediate (i.e. type $a$ mechanisms)..$^{12}$ Mechanisms of the type $b$ where $[\mathrm{HE}]^{\bullet+}$ transfers a $\mathrm{H}$ atom to a ground state, closed shell species are absent from the literature. However, comparison of the reduction potentials suggests that the reduced catalyst [Ir1 $]^{-}$is 
not a strong enough reductant to engage in a direct SET with cinnamate derivatives, which would be a requirement of type a mechanisms (reduction potentials in MeCN referenced to SCE: $\mathrm{E}_{\frac{1}{2}(\mathbf{I r} 1)}=-1.54 \mathrm{~V},{ }^{3 \mathrm{~d}} \mathrm{E}_{1 / 2(1 \mathrm{a})}=-1.87 \mathrm{~V},{ }^{19}$ Scheme $\left.2 \mathrm{C}\right)$. To assess the feasibility of type $b$ mechanism, we resourced to DFT modelling of the reaction (M06-2X/6-31+G(d,p), see ESI for details). ${ }^{20}$ Pleasingly, we could find transition states for the HAT step from [HE] ${ }^{\bullet+}$ to either position $\alpha$ or $\beta$ of $\mathbf{1 a}$, both of which are predicted to be readily accessible energetically ( $\Delta \mathrm{G}^{\ddagger}$ $=14.9$ and $19.0 \mathrm{kcal} / \mathrm{mol}$ for $\alpha$ and $\beta$, respectively, Scheme 2D). Moreover, computed reduction potentials of the resulting radicals to their corresponding carbanions were consistent with their easy reduction by $[\operatorname{Ir} 1]^{-}\left(\mathrm{E}_{1 / 2}\left(\mathbf{l a H}_{\alpha}\right)=-1.43 \mathrm{~V}\right.$, Scheme 2C). ${ }^{21,22}$

All this evidence, thus, provides support for a mechanism as depicted in Scheme 2E, where excitation of Ir1 by visible light enables it to oxidise $\mathrm{HE}$ to its radical cation $[\mathrm{HE}]^{\bullet+}$. Subsequently, $[\mathrm{HE}]^{\bullet+}$ transfers a $\mathrm{H}$ atom to the alkene 1 a giving place to a benzylic radical $\left[\mathbf{1 a H}_{\alpha}\right]^{\bullet}$, which is finally further reduced by SET from [Ir1] ${ }^{-}$and protonated to give the reduced product $\mathbf{2 a}$.

\section{Conclusions}

In conclusion, we have developed a simple method for the photoreduction of olefins which enables the use of moderately electron-deficient, synthetically meaningful substrates with good functional group compatibility. Our mechanistic investigations support a hydrogen atom transfer to the substrate as the key step which enables the reduction to proceed without requiring the generation of a very highly reducing medium. We believe this unprecedented mode of substrate activation offers new opportunities for photoredox transformations by enabling the generation of radical intermediates that otherwise are not easily accessible.

\section{Conflicts of interest}

There are no conflicts to declare.

\section{Acknowledgements}

We gratefully acknowledge Queen Mary University of London for partially funding this research. NAL thanks the European Commission for an MSCA fellowship (Project LIONCAT). JMO thanks QMUL for a PhD scholarship. This research utilised Queen Mary's Apocrita HPC facility, supported by QMUL Research-IT. http://doi.org/10.5281/zenodo.438045.

\section{Notes and references}

1 J. A. Kent, T. V. Bommaraju and S. D. Barnicki, Eds., Handbook of Industrial Chemistry and Biotechnology, Springer International Publishing, 2017.
2 (a) D. Wang and D. Astruc, Chem. Rev., 2015, 115, 66216686; (b) L. Lloyd, in Fundamental and Applied Catalysis, eds. M. Twigg and M. Spencer, Springer US, 2011, pp. 73-117.

3 (a) R. C. McAtee, E. J. McClain and C. R. J. Stephenson, Trends Chem., 2019, 1, 111-125; (b) L. Marzo, S. K. Pagire, O. Reiser and B. König, Angew. Chem. Int. Ed., 2018, 57, 10034-10072; (c) C. R. J. Stephenson, T. P. Yoon and D. W. C. MacMillan, Eds., Visible Light Photocatalysis in Organic Chemistry, WileyVCH, Weinheim, 2018; (d) C. K. Prier, D. A. Rankic and D. W. C. MacMillan, Chem. Rev., 2013, 113, 5322-5363.

4 (a) C. Pac, Y. Miyauchi, O. Ishitani, M. Ihama, M. Yasuda and H. Sakurai, J. Org. Chem., 1984, 49, 26-34; C. Pac, M. Ihama, M. Yasuda, Y. Miyauchi and H. Sakurai, J. Am. Chem. Soc., 1981, 103, 6495-6497.

5 Similarly, a few cases of formal hydrogenation of alkylidene malonates have been reported: (a) R. C. Betori and K. A. Scheidt, ACS Catal., 2019, 9, 10350-10357. (b) R. C. Betori, B. R. McDonald and K. A. Scheidt, Chem. Sci., 2019, 10, 33533359; (c) B. R. McDonald and K. A. Scheidt, Org. Lett., 2018, 20, 6877-6881.

6 Selected papers: (a) E. Speckmeier, P. J. W. Fuchs and K. Zeitler, Chem. Sci., 2018, 9, 7096-7103; (b) T. Rossolini, J. A. Leitch, R. Grainger and D. J. Dixon, Org. Lett., 2018, 20, 67946798; (c) K. N. Lee, Z. Lei and M. Y. Ngai, J. Am. Chem. Soc., 2017, 139, 5003-5006; (d) M. Nakajima, E. Fava, S. Loescher, Z. Jiang and M. Rueping, Angew. Chem. Int. Ed., 2015, 54, 8828-8832; (e) L. J. Rono, H. G. Yayla, D. Y. Wang, M. F. Armstrong and R. R. Knowles, J. Am. Chem. Soc., 2013, 135, 17735-17738.

7 Y. Nakano, M. J. Black, A. J. Meichan, B. A. Sandoval, M. M. Chung, K. F. Biegasiewicz, T. Zhu and T. K. Hyster, Angew. Chem. Int. Ed., 2020, DOI: 10.1002/anie.202003125.

8 For a review on multi-photon excitation, see: (a) F. Glaser, C. Kerzig and O. S. Wenger, Angew. Chem. Int. Ed., 2020, 2-21. For selected recent papers, see: (b) M. Giedyk, R. Narobe, S. Weiß, D. Touraud, W. Kunz and B. König, Nat. Catal., 2020, 3, 40-47; (c) T. U. Connell, C. L. Fraser, M. L. Czyz, Z. M. Smith, D. J. Hayne, E. H. Doeven, J. Agugiaro, D. J. D. Wilson, J. L. Adcock, A. D. Scully, D. E. Gómez, N. W. Barnett, A. Polyzos and P. S. Francis, J. Am. Chem. Soc., 2019, 141, 17646-17658; (d) C. Kerzig and O. S. Wenger, Chem. Sci., 2019, 10, 1102311029.

9 (a) N. G. W. Cowper, C. P. Chernowsky, O. P. Williams and Z. K. Wickens, J. Am. Chem. Soc., 2020, 142, 2093-2099; (b) H. Kim, H. Kim, T. H. Lambert and S. Lin, J. Am. Chem. Soc., 2020, 142, 2087-2092.

10 (a) T. Horngren, M. S. Taylor, M. Czyz and A. Polyzos, 2020, ChemRxiv: $10.26434 /$ chemrxiv.12235928.v1. For a related pioneering report, see: (b) D. R. Arnold and A. J. Maroulis, J. Am. Chem. Soc., 1977, 99, 7355-7356.

11 (a) L. Capaldo, L. L. Quadri and D. Ravelli, Green Chem. 2020, DOI: 10.1039/D0GC01035A; (b) L. Capaldo and D. Ravelli, Eur. J. Org. Chem., 2017, 2056-2071;

12 Selected examples: (a) K. A. Margrey and D. A. Nicewicz, Acc. Chem. Res., 2016, 49, 1997-2006; (b) D. A. Nicewicz and D. S. Hamilton, Synlett, 2014, 25, 1191-1196. For selected papers, see: (c) J. Dong, X. Wang, Z. Wang, H. Song, Y. Liu and Q. Wang, Chem. Commun., 2019, 55, 11707-11710; (d) C. P. Seath, D. B. Vogt, Z. Xu, A. J. Boyington and N. T. Jui, J. Am. Chem. Soc., 2018, 140, 15525-15534; (e) S. Sumino, M. Uno, T. Fukuyama, I. Ryu, M. Matsuura, A. Yamamoto and Y. Kishikawa, J. Org. Chem., 2017, 82, 5469-5474; (f) C. Wang, K. Harms and E. Meggers, Angew. Chem. Int. Ed., 2016, 55, 13495-13498. 
13 (a) P. Z. Wang, J. R. Chen and W. J. Xiao, Org. Biomol. Chem., 2019, 17, 6936-6951; (b) J. Hu, J. Wang, T. H. Nguyen and N. Zheng, Beilstein J. Org. Chem., 2013, 9, 1977-2001; (c) Y. Nakano, K. F. Biegasiewicz and T. K. Hyster, Curr. Opin. Chem. Biol., 2019, 49, 16-24.

$14 \mathrm{HE}$ has also been applied as a hydride donor in organocatalytic transfer hydrogenation reactions: (a) C. Zheng and S. L. You, Chem. Soc. Rev., 2012, 41, 2498-2518; (b) S. G. Ouellet, A. M. Walji and D. W. C. Macmillan, Acc. Chem. Res., 2007, 40, 1327-1339.

$15 \mathrm{E} / \mathrm{Z}$ isomerisation of 1 a was observed as a significant sidereaction, particularly with $\operatorname{Ir}(\mathrm{ppy})_{3}$. For related isomerisations, see: ; (a) J. B. Metternich and R. Gilmour, J. Am. Chem. Soc., 2015, 137, 11254-11257; (b) K. Singh, S. J. Staig and J. D. Weaver, J. Am. Chem. Soc., 2014, 136, 52755278.

16 The degree of quenching by 1a was very small, being difficult to differentiate from experimental error. It is reasonable to assume that at least some quenching takes place, which was consistent with the observation of Z-1a in small amounts by ${ }^{1} \mathrm{H}$ NMR at early stages of the reaction (see ESI for details).

17 This has been frequently proposed in related transformations: (a) A. Trowbridge, D. Reich and M. J. Gaunt, Nature, 2018, 561, 522-527; (b) L. Qi and Y. Chen, Angew. Chem. Int. Ed., 2016, 55, 13312-13315.

18 For example in ref. 4(a), photoreduction of dimethyl fumarate by BNAH catalysed by Ru1 in MeOD gave $59 \% \mathrm{~d}_{2^{-}}$ and $37 \%$ d-dimethyl succinate, with only $4 \%$ non-deuterated product, while reaction with $4,4-\mathrm{d}_{2}-\mathrm{BNAH}$ in $\mathrm{MeOH}$ gave $6 \%$ mono- and $94 \%$ non-deuterated product. Similar numbers were reported for dimethyl maleate.

19 Calculated value. Compare to $-1.98 \mathrm{~V}$ experimental in $\mathrm{MeOH}$, see: T. Shiragami, H. Ankyu, S. Fukami, C. Pac, S. Yanagida, H. Mori and H. Fujita, J. Chem. Soc. Faraday Trans., 1992, 88, 1055-1061.

20 Y. Zhao and D. G. Truhlar, Theor. Chem. Acc., 2008, 120, $215-$ 241.

21 Calculated reduction potential for the isomeric radical $\left[\mathbf{1 a H}_{\beta}\right]^{\circ}$, obtained from $\mathrm{H}$ addition on the $\beta$ position, was $\mathrm{E}_{1 / 2}\left(\mathbf{l a H}_{\beta}\right)=-0.72 \mathrm{~V}$.

22 Method for calculating reduction potentials: H. G. Roth, N. A. Romero and D. A. Nicewicz, Synlett, 2016, 27, 714-723. 